\title{
Introduction
}

\section{A Marriage Story of Digitalisation and Sustainability?}

Can digitalisation be part of the solution to pressing sustainability challenges? Or are current developments going to impede a socio-ecological transformation? The answer is not black and white; it is complex and cross-cutting. We analyse key problems and give an outlook on possible solutions.

By Maike Gossen, Friederike Rohde and Tilman Santarius

$\mathrm{T}$ he United Nations Sustainable Development Goals (SDG) provide a guiding framework for worldwide policies that ensure a good life for present and future generations. If the SDG are to be met, resource consumption, greenhouse gas emissions, poverty and inequality have to be reduced as far as possible, while education, welfare, climate protection, and biodiversity should be promoted to expand and flourish in future years. Digitalisation, here understood as the permeation of various information and communications technology (ICT) devices and applications (hard- and software) into diverse areas of everyday life, society, and economy, may have significant implications on how the SDG can be achieved.

On the positive side, digital tools and applications may serve as levers and can trigger dynamic sustainability transformations in various sectors. For instance, several reports outline the potentials of digitalisation to increase energy efficiency, avoid resource waste, improve access to sustainable services, and innovate new sustainable practices (e.g. Digital Future Society 2020; GeSI/Accenture 2018; Hilty/Bieser 2017).
On the negative side, digitalisation can aggravate ongoing trends that are polarizing income or education level, and encouraging further economic growth that demands additional energy and resource consumption. This, in turn, could affect certain consumption patterns to become more instead of less energy or resource intensive (e. g. WBGU 2019; Lange/Santarius 2020). And with filter bubbles and echo chambers in digital space buttressing polarized discourses on climate change (Williams et al. 2015), successfully arguing sustainability cases is likely to become increasingly difficult. These examples suggest what has been found by more solid studies (e. g. Hilty/Aebischer 2015; Santarius et al. 2020): It is hard to draw an overall conclusion on how digitalisation impacts sustainability. Instead, politics, companies, and individuals must actively shape societal digitalisation processes to maximize their potentials for sustainability. Opportunities, risks and options for policies and actions need to be analysed in more detail.

This journal volume contributes to the endeavour to dive deeper into certain topics and to explore further the nexus of digitalisation and sustainability. In the following, we present the problems and challenges associated with digitalisation for sustainable development in infrastructure and services, hardware and software, energy systems and Artificial Intelligence (AI). Noticeably, the high expectations of digitalisation as a panacea have not yet been fulfilled and they depend heavily on the social, economic and political framework conditions. In particular, the question of what policies for a sustainable digitalisation can look like in distinctive fields of action is examined in the articles of this journal volume.

\section{Digital services and infrastructures}

Many of the digital services on the internet today have the character of public goods. Search engines, Social Media, video portals, and online shops and marketplaces provide key infrastructures and services to society and the economy. They are, by and large, non-excludable and generate common value to society, for instance by providing easy access to information anywhere and anytime. However, particularly the large service providers such as Google, Facebook, or Amazon are run by private actors and hence, follow commercial interests. Their databased business models use data to create private goods and sell personal information to third parties, particularly to adver- 
tising and profiling companies. The use of machine learning and large data sets (Big Data) further perfects such procedures. These uses generate challenges regarding privacy, data protection, and data tracking.

Another problem is the organization of many digital platforms as multi-sided markets that facilitate transactions between different user groups for free. In turn, these digital platforms also make money of data collection and extraction and selling data to third parties such as advertising companies (Srnicek 2017). To intensify data extraction, platforms employ algorithms promoting content that is more likely to trigger user engagement. As a result, information is assessed regarding its utility for the platform, not for the user. A second major problem for platform users relates to platform markets' monopolization tendencies. Today, data, capital and power are increasingly centralized in the hands of a few platform incumbents. This increased market power gives the major platforms a "too big to fail" status, often rendering them additional leverage against social and environmental protection legislation.

\section{Private actors with commercial interests}

Moreover, basic internet infrastructures (data centres and broadband networks) are currently run by private companies. For instance, more than half of the ocean cable data capacities are owned by four content providers (Alphabet, Microsoft, Facebook, Amazon). Further, dependence has grown immensely on cloud platforms that provide the infrastructure to store, analyse, and utilize ever larger parts of companies' and individuals' private data (Staab/Nyckel 2019). That these services are largely controlled by US and Chinese companies is not only alarming from a geopolitical point of view but is also problematic concerning compliance with data protection law; for instance, the European General Data Protection Regulation (GDPR) does not apply abroad and is partly contradictory to foreign legislation, e. g. to the US Cloud Act. Besides, online marketing for commercial purposes is being increasingly used not only on platforms serving digital public goods but throughout the internet. Techniques such as Big Data analytics and the personalization of advertisement make marketing more effective, but also more manipulative. They create unnecessary buying needs and promote unsustainable and excessive consumption.

To summarize, privatization, lack of data protection, online advertising, and digital business models bring challenges for distributive justice, digital self-determination, democratic participation, and ecological sustainability. What policy perspectives and possible actions are there for policy makers, companies and consumers to treat these challenges to nurture rather than contradict global sustainable development? Two articles in this volume deal with these questions. Vivian Frick, Maike Gossen, Jonas Pentzien, Dominik Piétron und Rena Tangens outline how the state could build a sovereign digital infrastructure and counter the centralization tendencies of the platform economy. The authors make suggestions for protecting infor-

\section{"The high expectations of digitalisation as a panacea have not yet been fulfilled and they depend heavily on the social, economic and political framework conditions."}

mational self-determination and civil and consumer rights, for example, by continuing to develop EU regulations such as the GDPR and ePrivacy. The second article, by Harriet Kingaby, focuses on digital advertising and its role in shaping the internet as a commercial space and as a space in which misinformation and hate speech can flourish. She deals with what Artificial Intelligence and algorithmic decision-making do for the pervasion of digital advertising and the manipulation of users through digital advertising. Her problem analysis leads to proposing policy interventions known from offline spaces to reduce overconsumption, disinformation, and hate speech on the internet.

\section{Hardware and software are interdependent}

The production, use, and disposal of ICT devices (hardware) as well as the design and use of software and the associated data traffic have ecological and social impacts. Digitalisation's material and immaterial basis must, therefore, be thought of more closely together. Design criteria such as longevity, reparability, and frugal use of resources play a decisive role in the endeavour to make producing and using hardware more sustainable. Open standards and licenses can establish important foundations for more sustainable software and hardware.

A large part of the environmental impact of ICT hardware occurs in the production phase. Therefore, the continued use of existing hardware is preferable to the purchase of new devices. A device's lifetime can be prolonged, for example, by modular design and options for repairability. However, without suitable software, a hardware's life span is often limited. For example, current operating systems are geared to current hardware configurations and can no longer be used securely once the manufacturer stops supporting them. A newly released operating system, on the other hand, may not be able to run on an older device. A lack of interoperability of software and (older) hardware in combination with the early end of software support means that still functional hardware is increasingly replaced before the end of the product life cycle (Manhart et al. 2016). Software, too, can often not be used in the long term as a result of an 
artificially enforced reduction in the life cycle of ICT systems through proprietary licenses and vendor lock-in.

Even though devices and applications are becoming relatively more efficient, the absolute consumption of energy and resources is rising due to the increasing size and higher performance and screen resolution of consumer electronics devices (Prakash et al. 2017). Any declining energy consumption on the part of end users is being far more than neutralized by higher energy intensities in hardware production and by an increasing demand for computational capacities and digital services in virtual clouds. To curb these countervailing effects, efficiency improvements must be flanked by strategies that improve hardware consistency so as to ensure compatibility with natural cycles, use fewer toxic materials, and increase the share of renewable resources in energy supply. At the same time, the countervailing effects can be treated by measures targeting more sufficiency-oriented use of hard- and software, e. g., using devices longer, or using less data-intensive services. The environmental impact of software results from the use of hardware and transmission processes (computing power, memory, networks) during its development, use, and deinstallation. Although the share of software-related energy consumption in the total energy consumption of ICT has not yet been reliably quantified, studies have shown that different software products that fulfil the same functional requirements can differ significantly in their power consumption (Gröger et al. 2018; Naumann et al. 2011).

Another challenge is posed by increasing resource requirements for producing terminal devices, servers, and networks. Digital devices consist of various metals, which are classified as conflict raw materials (INKOTA-netzwerk e. V. 2016) and are mined mainly in countries of the Global South under hazardous working conditions and massive violations of labour laws. In addition, there is considerable environmental pollution through for example contaminated soils, rivers and water reservoirs, deforestation, and air pollution (Pilgrim et al. 2017). Moreover, the product life cycle of many devices often ends with electronic waste when the products are not brought back into production as recycled resources.

On the waste disposal sites in countries of the Global South people live and work under inhumane conditions and health hazards to obtain recyclable raw materials from e-waste (Höfner/Frick 2019). Moreover, these processes lack transparency, as the production and disposal locations and conditions are often not traceable. What is a challenge for hardware, to some extent also applies to software. The production and programming of software is also often characterized by a lack of transparency. Proprietary software development delivers readily compiled and sealed code to users who have no way of checking whether the software is doing what it claims to be doing. Knowledge about the software is kept secret by companies, resulting in dependencies and knowledge monopolies.

These challenges are addressed by two articles in this volume that shed new light on the problems and discuss possible solutions. Johanna Pohl, Anja Höfner, Friederike Rohde, and
Erik Albers show that the growing number of digital devices not only entails growing energy and resource demands but can elicit massive human rights violations as well. Therefore, the authors argue, the interdependency of hardware and software has to be considered if sustainability challenges are to be met. Free and open-source software and open and repairable hardware could address many issues deriving from resource depletion and short product-lifetimes. Policy measures that enable and foster transparent production, longevity, and the "right to repair" as well as adjusted public procurement rules should be implemented to ensure sustainable hard- and software. Maximilian Voigt points out that the potentials of open hard- and software can only be realized if people's competences move beyond simply using digital technologies. Open education and collective reconfigurations of digital technologies should be a core focus in education. Makerspaces (open working and learning spaces) that foster knowledge about technical functions and promote self-determined use of technology can serve as places for new ideas and empowerment and thus contribute to digital literacy and sustainable practices of technology use.

\section{Digitalisation and transforming the energy system}

Renewable energies currently account for $42.1 \%$ of gross electricity consumption in the German electricity mix (UBA 2020). This significant share of renewables already poses challenges for grid operation at both distribution and transmission levels. Enabling a supply of $100 \%$ renewable electricity and, eventually, $100 \%$ renewable total energy consumption requires the intelligent control of load flows in the energy system. Digitalisation is an important prerequisite for a successful energy turnaround (dena 2016). Automatic control and networking possibilities are expanding the role of prosumers in the energy market. As digitalisation continues, small-scale players at the household level can be networked to create new organizational forms that fundamentally change existing value chains and even market structures.

In addition, intelligently connected energy systems are becoming increasingly important: So-called smart grids are expected to reduce energy system complexity and ensure power grid stability. For example, digital power transformers allow unexpected situations in the network to be recognized and controlled from the network control centre (Jendrischik 2020). However, a number of legal and technical questions are still open with regard to smart grids. For example, there are rules that allow network operators to switch off individual producers or consumers in the event of network bottlenecks in order to avoid a power outage. Yet, it is still unclear according to which criteria the regulation functions in a complex context of a multitude of flexibilities. What are needed are clear definitions of economic and technical criteria so as to enable algorithms and digital devices to provide support. Although grid level in the current energy system have been distributed between distri- 
bution system operators and transmission system operators, these responsibilities can change if complex interactions between grid levels occur. It is also unclear who owns or should have access to the large amount of data collected for operators. And this excessive data leads to a further ecological challenge since the high-resolution data from the grid causes additional emissions with each transfer.

A complete switch to renewable energies in industrial countries (such as Germany) is only realistic if the absolute energy demand is significantly reduced - roughly by $50 \%$ by 2050 (Prognos et al. 2020). It is largely undisputed that the digitalisation of the energy system will play an important role in this reduction. But does it make sense to completely digitize the energy system? Or would the energy and resources required for such a full-fledged digitalisation countervail any savings and efficiency gains? Particularly in the electricity sector, digitalisation processes aim to achieve positive environmental effects not only through direct savings by consumers but also at the systemic level of network control. Yet the effects on the system as a whole are currently not quantifiable. For some applications, it is unclear whether the high negative environmental impacts caused by producing and operating sensor technology, measuring devices, and ICT, and by transferring and using data, can be offset by the positive effects. Hence the pivotal question arises: How much digitalisation of the energy system is appropriate? Furthermore, the digitalisation of the energy system may increase its vulnerability. Against the background of far-reaching, potentially catastrophic and thus economically and socially hardly tolerable consequences such as power outages or the hacking of energy systems, it is key to design power supply systems as resilient as possible.

Again, two articles of this volume cover those challenges. Astrid Aretz, Swantje Gährs, Friederike Rohde, and Hendrik Zimmermann provide an overview of current environmental and social challenges regarding the digitalisation of the German energy system and argue for a more differentiated consideration of the relevant issues. A digitalised energy system should be ecological, resilient, inclusive, and open to diverse technologies. These aims should be realized by appropriately regulating market rules and technical standards and by measures to financially support consumers and enhance their relevant knowledge. Only appropriate framework conditions can enable decentralized structures and the coordination between the different actors from the energy system and other sectors (such as mobility). Saving energy with or despite digitalisation is a question that is covered in the article by Irmela Colaço. Current developments impede an ecological supportive use of digital energy technologies, and the repairability and durability requirements in the EU Eco-design Directive do not go far enough. There is a lack of political actions for strengthening prosumers, sharing communities and other forms of decentralized energy transition and digital sufficiency should be developed as a guiding principle for energy system transformation.

\section{"Digitalisation can aggravate trends that are polarizing income or education, and encourage economic growth that demands energy and resource consumption."}

\section{Expectations of Artificial Intelligence ...}

AI is the current "buzzword" when it comes to increasing efficiencies through digital applications. Additional positive contributions from AI-based systems are expected from networked energy and transport infrastructures, highly precise earth observation for climate change, new weather warning and forecasting systems, or improved solutions for waste and resource management, to mention but a few. And in fact, numerous projects for monitoring, modelling and managing ecosystems and biodiversity, for example in forestry, agriculture, and fisheries already use AI.

When discussing the sustainability contributions of AI applications, however, the energy and resource intensities of AI-based computational processes need to be taken into account. AI applications are often more energy intensive than conventional mathematical methods (e.g. regressions), even when the increasing energy efficiency of data centres is taken into account. For instance, deep learning algorithms, which analyse large amounts of data in artificial neural networks in order to recognize patterns and generate forecasts, consume particularly large amounts of energy. Moreover, AI applications indirectly affect resource consumption since they use an increasing share of hardware in data centres and terminal devices. Producing sensors and circuit boards involves metals such as tin, silver, platinum, or tungsten associated with ecological and social problems, especially in the Global South (see above).

\section{... exceed the actual environmental protection potential}

At the same time, positive environmental impacts of AI often depend on whether and in what form social transformation processes take place in parallel. For example, an AI-based optimization of the energy system provides limited value to reaching sustainability goals if renewable energies are not expanded. This expansion is, in turn, linked to a variety of societal factors that cannot be managed by technical means alone; various impediments have to be overcome, such as public scepticism about 
wind power plants or the dominance of lobby power by large conventional electricity providers. Hence the question is key: In which socio-economic framework conditions are AI-based solutions applied, by which actors and according to which guiding interests? Hence, besides technical opportunities and risks, the political economy of AI needs to be considered.

In the first corresponding article, Friederike Rohde, Maike Gossen, Tilman Santarius and Josephin Wagner reveal the diverse ecological, social, and economic challenges related to applying AI-based systems. They identify attempts to address those issues through regulation, rules, and guidelines for responsible AI. However, in current or prospected regulations, ecological impacts of those deep learning algorithms are not considered at all. Green cloud computing with energy efficiency standards for data centres could be one possibility to address the negative ecological impacts. Indeed, most effective would be measures such as taxes on carbon emissions, resources, and appropriate public procurement guidelines. And above that, AI-based applications have to be used with caution and in areas where it really makes sense, as Sarah-Indra Jungblut argues. Her article focuses on AI-based applications and their contribution to environmental or climate protection. These applications can be used to reduce energy consumption or food waste, or for predictive maintenance. However, regarding their ecological impacts and possible ethical problems, those technologies must be implemented with due precaution and in a reasonable manner to avoid overkill.

The last two articles of this volume deal with the overarching question of how digitalisation can contribute to the socioecological transformation, and in this sense take a bird's eye view. Josephin Wagner and Steffen Lange discuss whether digitalisation can support growth independence and sufficiencyoriented lifestyles. Sarah Ganter provides an overview of how the discourse on a digital tax for financing the socio-ecological transformation has developed in recent years. She explains the weaknesses in the taxation of multinational corporations in the digital economy and attempts by the OECD to reform the international tax system.

\section{References}

dena (2016): Grundsatzpapier der Plattform Digitale Energiewelt. www.dena.de/fileadmin/dena/Dokumente/Presse__Medien/2016-06-06_ Grundsatzpapier_der_Plattform_Digitale_Energiewelt.pdf

Digital Future Society (2020): Risks and opportunities of emerging tech in the climate decade. https://digitalfuturesociety.com/report/risks-andopportunities-of-emerging-tech-in-the-climate-decade/

GeSI/Accenture (2018): Enabling the Global Goals: Evidence of digital solutions' impact on achieving the Sustainable Development Goals (SDGs). https://etno.eu/datas/press_corner/press-releases/2018/GeSI_AS_2018_ Digital_Enabling_the_Global-Goals.pdf

Gröger, J./Köhler, A./Naumann, S./Filler, A./Guldner, A./Kern, E./Hilty, L./ Maksimov, Y. (2018): Entwicklung und Anwendung von Bewertungsgrundlagen für ressourceneffiziente Software unter Berücksichtigung bestehender Methodik. Abschlussbericht. Dessau-Roßlau, Umweltbundesamt.

Hilty, L. M./Aebischer, B. (eds.) (2015): ICT Innovations for Sustainability. Cham, Springer.
Hilty, L. M./Bieser, J. (2017): Opportunities and Risks of Digitalization for Climate Protection in Switzerland. Zurich, University of Zurich.

Höfner, A./Frick, V. (2019): Was Bits und Bäume verbindet. Digitalisierung nachhaltig gestalten. Dokumentation der Konferenz "Bits \& Bäume”. München, Oekom.

INKOTA-netzwerk e. V. (2016): INKOTA-Infoblatt 2: Konfliktrohstoffe. https://webshop.inkota.de/produkt/download-inkota-infoblaetter/inkotainfoblatt-2-konfliktrohstoffe

Jendrischik, M. (2020): Digitale Trafos: So macht E.ON aus Stromnetz steuerbares Smart Grid. www.cleanthinking.de/digitale-trafos-eon-smart-grid/

Lange, S./Santarius, T. (2020): Smart Green World? Making Digitalization Work for Sustainability. München, Oekom.

Manhart, A./Blepp, M./Fischer, C./Graulich, K./Prakash, S./Priess, R./ Schleicher, T./Tür, M. (2016): Resource Efficiency in the ICT Sector. Final Report. Hamburg, Greenpeace.

Naumann, S./Dick, M./Kern, E./Johann, T. (2011): The greensoft model: A reference model for green and sustainable software and its engineering. In: Sustainable Computing: Informatics and Systems 1/4: 294-304.

Pilgrim, H./Groneweg, M./Reckordt, M. (2017): Ressourcenfluch 4.0: Die sozialen und ökologischen Auswirkungen von Industrie 4.0 auf den Rohstoffsektor. Berlin, PowerShift.

Prakash, S./Gröger, J./Hipp, T./Rodem, I./Borgstedt, S./Schlösser, A./Stobbe, L./Proske, M./Riedel, H./Chancerel, P., et al. (2017): Ermittlung und Erschließung des Energie- und Ressourceneffizienzpotenzials von Geräten der Unterhaltungselektronik. Dessau-Roßlau, Umweltbundesamt.

Prognos/Öko-Institut/Wuppertal-Institut (2020): Klimaneutrales Deutschland. Berlin, Agora Verkehrswende und Stiftung Klimaneutralität.

Santarius, T./Pohl, P./Lange, S. (2020): Digitalization and the Decoupling Debate: Can ICT Help to Reduce Environmental Impacts While the Economy Keeps Growing? In: Sustainability 12/18: 7496.

Srnicek, N. (2017): Platform Capitalism. Cambridge, Polity.

Staab, P./Nyckel, E. (2019): Digitaler Kapitalismus und Unternehmenssoftware-Herrschaft der Betriebssysteme? In: WISO Direkt 08/2019.

Umweltbundesamt (2020): Erneuerbare Energien in Zahlen. www. umweltbundesamt.de/themen/klima-energie/erneuerbare-energien/ erneuerbare-energien-in-zahlen\#uberblic

WBGU (2019): Unsere gemeinsame digitale Zukunft. Berlin, WBGU.

Williams, H. T. P./McMurray, J. R./Kurz, T./Lambert, F. H. (2015): Network analysis reveals open forums and echo chambers in social media discussions of climate change. In: Global Environmental Change 32: 126-138.
Maike Gossen and Friederike Rohde are researchers at the IÖW Institut für ökologische Wirtschaftsforschung (IÖW) Potsdamer Str. 105, 10785 Berlin. E-mail: maike.gossen@ioew.de, friederike.rohde@ioew.de, Tel.: +49 308845940

Tilman Santarius is Professor of Social-Ecological Transformation and Sustainable Digitalization at the Technical University of Berlin and the Einstein Center Digital Futures. Technical University of Berlin, Marchstraße 23, 10587 Berlin. E-mail: santarius@tu-berlin.de, Tel.: +49 3031478838 